\title{
THE EFFECTS OF POSSIBLE CONTAMINATION ON THE RADIOCARBON DATING OF THE DEAD SEA SCROLLS I: CASTOR OIL
}

\author{
Kaare L Rasmussen ${ }^{1} \bullet$ Johannes van der Plicht ${ }^{2} \bullet$ Frederick H Cryer $^{3} \bullet$ Gregory Doudna $^{4}$ \\ Frank M Cross ${ }^{5} \cdot$ John Strugnell ${ }^{6}$
}

\begin{abstract}
Some fragments of the Dead Sea Scroll manuscripts were contaminated with castor oil in the late 1950s. We have conducted experiments in order to establish if the AAA pretreatment cleaning procedures conducted on Dead Sea Scroll manuscript samples in the last two dating series (Bonani et al. 1992; Jull et al. 1995) were effective in removing oil contamination. Our experiments show that not all oil contamination can be expected to have been removed by the acid-alkaline-acid (AAA) pretreatment, and that the radiocarbon ages previously reported therefore cannot be guaranteed to be correct. Any samples contaminated with castor oil were most likely reported with ages that are too young by an unknown amount.
\end{abstract}

\section{INTRODUCTION}

It has long been clear from the early literature on the initial work conducted on the Dead Sea Scrolls (hereafter DSS) that the first efforts to clean and get readings from the scroll fragments entailed exposing them to potentially contaminating substances that could have caused consequences in later radiocarbon analysis (Bonani et al. 1992; Jull et al. 1995; Doudna 1998 and references therein). As discussed elsewhere (Doudna 1999) the fragments have also been exposed in the course of efforts at conservation to a variety of further treatments (Caldarero 1995; Boyd-Alkalay and Libman 1998). Much of this contamination was either unavoidable under the circumstances or simply the least bad alternative in the process of providing for the survival of the texts for study by later generations. The early editors and conservators thought at the time that the use of castor oil to clean and restore legibility to the skins was necessary. Unhappily, we often discover that measures thought to be helpful in one respect prove to be inexpedient from another vantage point.

Castor oil was used extensively by the original team of DSS editors both to clean the texts and to make the readings clearer. One of the authors of the present study, FM Cross, recounts the introduction of castor oil in 1953, first in the cleaning of fragments of $4 \mathrm{Q} 51\left(4 \mathrm{QSam}{ }^{\mathrm{a}}\right)$, and subsequently other Cave 4 materials:

The subject was one that troubled me when the first series of samples were taken for testing (1990-1991, Zürich). I thought the tests might come out much too late because of [the] modern date of the castor oil. I conveyed this feeling to Magen Broshi and John Strugnell.

More recently Boyd-Alkalay and Libman (1998) have brought information to light indicating that the DSS fragments were also extensively treated in 1963 with a product called British Museum Leather Dressing (BMLD) by a visiting conservator from the British Museum in London. To the knowledge of one of the present authors, J Strugnell, the British Museum treated 6-10 plates of fragments (e.g. 4Q448). We shall have to defer analysis of the possible effects of BMLD on Qumran text ${ }^{14} \mathrm{C}$ dating to a later paper. But it can be noted here that a conservator at the British Museum states that the tendency in the 1960s was to employ BMLD on a regular basis (Wills personal communica-

\footnotetext{
${ }^{1}$ Carbon-14 Dating Laboratory, National Museum of Denmark, Ny Vestergade 11, DK-1471 Copenhagen K, Denmark.

E-mail: kaare.lund.rasmussen@natmus.dk.

${ }^{2}$ Centrum voor Isotopen Onderzoek, Nijenborgh 4, 9747 AG Groningen, the Netherlands

${ }^{3}$ Søndertoft 1, Kværs, DK-6300 Graasten, Denmark

${ }^{4} 1700$ Marion Street, Clearwater, Florida 33756, USA

${ }^{5}$ Department of Near Eastern Languages and Civilizations, Harvard University, 6 Divinity Avenue, Cambridge Massachusetts 02138, USA

${ }^{6}$ The Divinity School, Harvard University, 45 Francis Street, Massachusetts 02138, USA
} 
tion 2000). In our view it remains to be shown that the modified acid-alkaline-acid (AAA) cleaning procedure employed by the ${ }^{14} \mathrm{C}$ laboratories at Zürich and Tucson, which conducted the first two series of ${ }^{14} \mathrm{C}$ datings of the DSS, was capable of removing all traces of these contaminants from manuscript samples.

As far as castor oil is concerned, it was thought essential by the Copenhagen group to determine whether the AAA cleaning procedure was capable of removing all traces of this specific contaminant from manuscript fragments and, if necessary, to devise a cleaning procedure capable of removing castor oil from manuscript fragments. An experimental procedure for testing the consequences of oil contamination on ${ }^{14} \mathrm{C}$ dating of manuscript samples is described below.

An important issue in the discussion is the extent of the problem, i.e., to what extent were Qumran text fragments exposed to oil contamination? Contamination of a sample with synthetic fossil oil (petroleum or its derivatives, containing ancient carbon), if it was not removed from the sample by the cleaning procedure, would give a misleading ${ }^{14} \mathrm{C}$ date in an "older" direction. Contamination of a sample with an oil derived from a natural modern plant (such as castor, sunflower, thistle, peanut, or rapeseed [canola] oil), if not removed by the pretreatment, would give a misleading ${ }^{14} \mathrm{C}$ age that was "younger" than the true age of the sample. We have accounts from the early editors which unanimously agree that castor oil—and not old oils-were used on the DSS in the Rockefeller Museum in the 1950s.

The use of castor oil on texts ranged from only occasional or sparing use, in conjunction with poorly legible sections of text, to application of castor oil to entire surfaces of fragments for general cleaning. There is a general consensus that fragments were never submerged in castor oil. It was applied with fine brushes, sometimes extensively, sometimes only at more obscure points. There is thus no a priori way to know from the outset whether a given Qumran text fragment from the Rockefeller Museum has been uncontaminated, or is minimally or entirely contaminated with oil. Rather, castor oil contamination must be assumed on all scroll fragments to be a potential problem that has to be overcome. Furthermore, owing to the varying degrees of the use of castor oil on the DSS, it will be impossible to devise any simple procedure for calculating a systematic chronological offset for any texts contaminated this way. One of the present authors, J Strugnell, recollects that after the application of castor oil the manuscripts appeared shiny, whereas untreated fragments appeared matte or buff. Whether this still holds now, some 45 years later, is difficult to verify, because it is difficult to determine precisely which manuscript fragments were treated with castor oil.

Available reports indicate that treatment of the DSS with castor oil, at least for cleaning purposes, had ceased by the early 1960s. All reports concerning the use of castor oil on fragments in the Rockefeller Museum indicate that the use of castor oil occurred in the 1950s and there is no evidence it was used after the disbanding of the editorial team in 1960. This is an important detail because atmospheric ${ }^{14} \mathrm{C}$ activity reached a maximum in 1963 . But the use of castor oil off the shelf probably would not reflect the impact of this high activity oil before 1965 or maybe even later. Also the Cave 1 scrolls kept at the Israel Museum's Shrine of the Book (e.g. 1QIsa ${ }^{\mathrm{a}}, 1 \mathrm{QH}{ }^{\mathrm{a}}, 1 \mathrm{QApocGen}, 1 \mathrm{QpHab}$, $1 \mathrm{QS}$, as well as other texts at the Shrine) were not subjected to castor oil contamination while at that Museum (Broshi personal communication 2000). The spectrum of possible castor oil contamination of the Qumran text samples subjected to ${ }^{14} \mathrm{C}$-dating thus runs from none to slight to total.

\section{EXPERIMENTAL PROCEDURE}

In order to determine the potential problems with oil contamination we conducted two experiments. In the first experiment three $1 \mathrm{~cm}^{2}$ pieces of a French monastic medieval parchment kindly put at our 
disposal by Erik Petersen of the Royal Library of Copenhagen were subjected to contamination by oil. One sample (KLR-1896) was saturated in modern castor oil, the oil of the Ricinus plant. Another (KLR-1895) was saturated in oil derived from petroleum products i.e. of infinite ${ }^{14} \mathrm{C}$-age. A third sample (KLR-1894) was kept in its natural state as a control. We have no knowledge of the use of "old" oil on the DSS, but we have also included old oil in the study because the effect in ${ }^{14} \mathrm{C}$-years is expected to be in the opposite direction and numerically larger.

The reason that we saturated the samples in oil rather than just brushing them or coating them with oil, is that in all cases in our experience the DSS samples showed a pronounced tendency to soak up any oil added to the surface within minutes. It is generally not feasable to coat a DSS fragment with oil, as the oil disappears quickly into the interior of the sample. It would therefore be a rather arbitrary amount of oil that would be added if the samples were not soaked. The fact that we saturated the samples does, of course, give us a worst-case scenario. It is likely that many of the DSS fragments received less oil than that of saturation. On the other hand, it also seems likely that those fragments that in the first place needed brushing up with oil in order to be read, might well have been subjected to repeated treatments of oil when different scholars needed to read them or even the same scholar needed to confirm a reading, and thus approaching a situation of saturation.

All three samples were subjected in Copenhagen to the same modified AAA-treatment that was used in the Arizona series on Dead Sea texts that were reported in 1995. The treatment consisted of $1 \mathrm{~N}$ $\mathrm{HCl}$, water, $0.1 \mathrm{wt} \% \mathrm{NaOH}$ and water, 10 minutes each, followed by reacidification in $\mathrm{HCl}$ and rinsing in water. Subsequently the samples were dried in an oven at $60{ }^{\circ} \mathrm{C}$. The samples were then graphitized and dated at the Groningen ${ }^{14} \mathrm{C}$ AMS facility.

Table 1 lists sample weights in the natural state, weights after saturation in oil, and weights after AAA treatment. The results in terms of ${ }^{14} \mathrm{C}$ age and $\delta^{13} \mathrm{C}$ are listed as well. A calibrated date of AD 1260-1290 for the uncontaminated piece (KLR-1894) gives an age that is in agreement with text analysis of the French monastic medieval manuscript (Stuiver et al. 1998).

Table 1 Results of radiocarbon datings of untreated and artificially contaminated samples

\begin{tabular}{|c|c|c|c|c|c|c|c|c|}
\hline $\begin{array}{l}\text { Lab nr } \\
\text { KLR- }\end{array}$ & $\begin{array}{c}\text { Lab nr } \\
\text { GrA- }\end{array}$ & Treatment & $\begin{array}{c}\text { Weight } \\
\text { natural } \\
(\mathrm{mg})\end{array}$ & $\begin{array}{c}\text { Weight } \\
\text { with oil } \\
(\mathrm{mg})\end{array}$ & $\begin{array}{l}\text { Weight } \\
\text { after } \\
\text { AAA } \\
(\mathrm{mg})\end{array}$ & $\begin{array}{l}{ }^{14} \mathrm{C} \text {-age } \\
\pm 1 \sigma\end{array}$ & $\begin{array}{c}\text { Calibrated } \\
\text { age at } \pm 1 \sigma\end{array}$ & $\begin{array}{c}\delta^{13} \mathrm{C} \\
\% o \\
\text { VPDB }\end{array}$ \\
\hline 1894 & 13929 & Untreated & 27.0 & 27.0 & 22.4 & $750 \pm 40$ & AD $1260-1290$ & -22.43 \\
\hline 1895 & 13930 & Old oil & 24.7 & 31.5 & 22.8 & $2030 \pm 40$ & 90 BC-AD 20 & -23.10 \\
\hline 1896 & 13931 & Modern oil & 27.9 & 36.5 & 25.9 & $540 \pm 40$ & AD $1330-1430$ & -23.48 \\
\hline
\end{tabular}

The sample treated with old oil (KLR-1895), after AAA treatment, gave a ${ }^{14} \mathrm{C}$ age $1280{ }^{14} \mathrm{C}$-years older than the untreated sample (KLR-1894). On the other hand the sample treated with modern oil (KLR-1896) is, after AAA treatment, $210{ }^{14} \mathrm{C}$-years younger than expected. Both offsets are in the directions predicted if the respective contaminants had not been fully removed by the AAA cleaning procedure.

The second experiment was partly a repeat of the first experiment. Four $1 \mathrm{~cm}^{2}$ pieces of the same French monastic medieval parchment were subjected to oil contamination. One sample (KLR-2316) was saturated in modern castor oil, two (KLR-2315 and KLR-2318) were saturated in old oil, and one sample (KLR-2317) was kept in its natural state as a control. Three of the samples (KLR-2315, -2316, and -2317) received the modified cold AAA-treatment used in the Arizona series ( $1 \mathrm{M} \mathrm{HCl}$, 
water, $0.1 \mathrm{wt} \% \mathrm{NaOH}$, water, reacidification and rinsing in water). KLR-2318 received $40-50{ }^{\circ} \mathrm{C}$ warm alkaline treatment, similar to the Zürich approach.

These four samples together with a sample of pure castor oil and a sample of the pure petroleumderived oil were graphitized and dated in Groningen. The results are listed in Table 2.

Table 2 Repeat experiment and the radiocarbon dates of the contaminants

\begin{tabular}{cclcccccc}
\hline $\begin{array}{c}\text { Lab nr } \\
\text { KLR- }\end{array}$ & $\begin{array}{c}\text { Lab nr } \\
\text { GrA- }\end{array}$ & Treatment & $\begin{array}{c}\text { Weight } \\
\text { natural } \\
(\mathrm{mg})\end{array}$ & $\begin{array}{c}\text { Weight } \\
\text { with oil } \\
(\mathrm{mg})\end{array}$ & $\begin{array}{c}\text { Weight } \\
\text { after AAA } \\
(\mathrm{mg})\end{array}$ & $\begin{array}{c}{ }^{14} \mathrm{C} \text {-age } \\
\pm 1 \sigma\end{array}$ & $\begin{array}{c}\text { Calibrated } \\
\text { age at } \pm \sigma \\
(\mathrm{AD})\end{array}$ & $\begin{array}{c}\delta^{13} \mathrm{C} \\
\% 0\end{array}$ \\
\hline 2315 & 14044 & Old oil & 31.7 & 38.2 & 27.3 & $1670 \pm 45$ & $260-430$ & -23.04 \\
2316 & 14043 & New oil & 24.9 & 32.7 & 23.3 & $475 \pm 45$ & $1410-1450$ & -23.53 \\
2317 & 14042 & Untreated & 23.9 & 23.9 & 19.3 & $770 \pm 45$ & $1220-1290$ & -22.61 \\
2318 & 14038 & Old oil & 24.0 & 30.3 & 17.9 & $1670 \pm 45$ & $260-430$ & -22.84 \\
2323 & 14051 & Pure old oil & - & - & - & $>45,000$ & & -27.00 \\
2324 & 14052 & Pure modern oil & - & - & - & $111.5 \pm 0.6 \%$ & & -28.80 \\
\hline
\end{tabular}

The untreated sample, KLR-2317, gave a conventional age of $770 \pm 45{ }^{14} \mathrm{C}$-years BP, which agrees within error limits with the age of the untreated sample from the first experiment, KLR-1894, which was $750 \pm 40{ }^{14} \mathrm{C}$-years BP. Again, the sample saturated with old oil, KLR-2315, dated to a significantly older age, $1670 \pm 45{ }^{14} \mathrm{C}$-years $\mathrm{BP}$, than the untreated sample. The reason for the difference between KLR-2315 and KLR-1895 (cited above) could be that the two samples had different oil-saturations, probably due to varying properties, such as porosity or permeability, of the parchment between the two sampling locations. It is to be noted that the samples with old oil treated with cold and warm AAA both dated to identical ages, $1670 \pm 45{ }^{14} \mathrm{C}$-years $\mathrm{BP}$, so there is no significant difference in the cold and the warm AAA-pretreatment as regards their ability to remove oil contamination. And again, as in the first experiment, the sample saturated in young castor oil, KLR-2316, dated significantly younger than the untreated sample: $295{ }^{14} \mathrm{C}$-years difference in the direction predicted if the contaminant had not been removed by the AAA cleaning procedure.

The ages of the pure old and pure modern oils allow us to calculate how much of the oil was removed from the parchment by the AAA-treatment. The percentages of oil contamination removed by the AAA are listed in Table 3 . The first two columns in Table 3 list the ${ }^{14} \mathrm{C}$ activity ratio ${ }^{14} \mathrm{a}$ (see Mook and van der Plicht 2000) and the percent of oil calculated from the ${ }^{14} \mathrm{a}$. The last two columns of Table 3 give the percent of oil introduced into the sample (calculated from the sample weights in Table 1 and 2), and finally, by subtraction, the percent of oil which was removed from the sample by the AAA-treatment.

For the old oil saturated samples the percent oil inferred from the activity ratios, ${ }^{14} \mathrm{a}$, to be present in samples have been calculated as:

$$
\mathrm{PCT}_{\text {oil calculated from 14a }}=\left({ }^{14} \mathrm{a}_{\text {sample }}-{ }^{14} \mathrm{a}_{\text {untreated-sample }}\right) /\left({ }^{14} \mathrm{a}_{\text {old-oil }}-{ }^{14} \mathrm{a}_{\text {untreated-sample }}\right) \times 100
$$

For the samples saturated with new oil the percent oil inferred has been calculated as:

$$
\mathrm{PCT}_{\text {oil calculated from 14a }}=\left({ }^{14} \mathrm{a}_{\text {sample }}-{ }^{14} \mathrm{a}_{\text {untreated-sample }}\right) /\left({ }^{14} \mathrm{a}_{\text {new-oil }}-{ }^{14} \mathrm{a}_{\text {untreated-sample }}\right) \times 100
$$

The value for the untreated sample is: ${ }^{14} \mathrm{a}_{\text {untreated-sample }}=91.022 \%$. The values for the old and the new oils, as also given in Table 2, are: ${ }^{14} \mathrm{a}_{\text {old-oil }}=0$ and ${ }^{14} \mathrm{a}_{\text {new-oil }}=111.5 \%$. 
The percent oil-saturation is calculated as:

$$
\mathrm{PCT}_{\text {oil-saturated }}=\left(\mathrm{Weight}_{\mathrm{with} \mathrm{oil}}-\mathrm{Weight}_{\text {natural }}\right) / \mathrm{Weight}_{\text {with oil }} \times 100
$$

and the percentage of oil removed by the AAA-treatment is calculated as:

$$
\mathrm{PCT}_{\text {oil removed by AAA }}=\mathrm{PCT}_{\text {oil-saturated }}-\mathrm{PCT}_{\text {oil calculated from 14a }}
$$

It should be noted that it would not be safe to calculate the amount of oil left in the samples from the measured $\delta^{13} \mathrm{C}$-values, because it is uncertain precisely how the stable carbon isotopes of the oil are fractionated by the cleaning procedure, the AAA, the burning and the graphitization, and also because of the finite uncertainty in the $\delta^{13} \mathrm{C}$-measurements. It must be stressed that the $\delta^{13} \mathrm{C}$-measurements should not be looked upon as an attempt to determine the $\delta^{13} \mathrm{C}$ of the pristine samples, but rather as a working tool used to monitor the precise isotopic fractionation that has taken place during the more or less rough sample preparaion. In the end it is used solely as a small correction to the radiocarbon age.

Table 3 shows that the samples were saturated at between 17 and $24 \mathrm{wt} \%$ oil. Between 6 and $12 \mathrm{wt} \%$ of the oil was removed by the AAA-treatment. This leaves about half of the oil, or between 11 and $16 \mathrm{wt} \%$ oil, in place in the samples after AAA-treatment. This oil contamination was converted to graphite together with the manuscript itself, and gave rise to the erroneous ${ }^{14} \mathrm{C}$ ages. As is to be expected there seems to be no systematic difference between the quantities of old and new oil removed by the AAA treatment.

\begin{tabular}{|c|c|c|c|c|c|c|}
\hline $\begin{array}{l}\text { Lab nr } \\
\text { KLR- }\end{array}$ & $\begin{array}{l}\text { Lab nr } \\
\text { GrA- }\end{array}$ & Treatment & $\begin{array}{l}{ }^{14} \mathrm{C} \text { activity } \\
\text { ratio, }{ }^{14} \mathrm{a} \\
\quad \pm 1 \sigma\end{array}$ & $\begin{array}{l}\text { PCT oil } \\
\text { calculated } \\
\text { from }{ }^{14} \mathrm{a} \\
\text { (after } \\
\text { AAA) }\end{array}$ & $\begin{array}{c}\text { PCT oil } \\
\text { saturated } \\
\text { (before } \\
\text { AAA) }\end{array}$ & $\begin{array}{l}\text { PCT oil } \\
\text { removed } \\
\text { by AAA }\end{array}$ \\
\hline 1895 & 13930 & Old oil & $77.67 \pm 0.39$ & 15 & 22 & 7 \\
\hline 1896 & 13931 & New oil & $93.50 \pm 0.47$ & 12 & 24 & 12 \\
\hline 2315 & 14044 & Old oil & $81.23 \pm 0.46$ & 11 & 17 & 6 \\
\hline 2316 & 14043 & New oil & $94.26 \pm 0.53$ & 16 & 24 & 8 \\
\hline 2318 & 14038 & Old oil & $81.23 \pm 0.46$ & 11 & 21 & 10 \\
\hline
\end{tabular}

Table 3 Calculated results of the degree of removal of contaminants

Taking the average of the activity ratios of KLR-1896 and KLR-2316 in Table 3, and subtracting the activity ratio of the uncontaminated sample, $91.022 \%$, it can be seen that the contamination with new oil results in a difference of about $2.86 \%$ (equivalent to the average of the age differences of 210 and $295{ }^{14} \mathrm{C}$-years mentioned above). The same amount of contamination on a 2000 -year-old manuscript would result in an error of approximately $300{ }^{14} \mathrm{C}$-years. But these experiments were done on fully oil-saturated samples. The saturations were obtained by submerging each sample in the oil and letting the sample sit in the oil for several minutes. From the descriptions of treatment procedures of the DSS it must be considered unlikely that any Qumran text fragments were fully saturated in castor oil. It is therefore difficult to assess how much oil would have been introduced in any single contaminated Qumran text fragment. Most likely the degree of saturation varied from fragment to fragment, and perhaps from place to place on the same fragment, as is also seen in this experiment (KLR-2315 vs. KLR-1895). The age offset due to contamination by castor oil on Qumran text samples would therefore probably be less than, and rarely as much as, the estimated $300{ }^{14} \mathrm{C}$-years error inferred from this study of castor-oil-contaminated samples. 


\section{CONCLUSION}

Our experiments demonstrate that the AAA-treatment used in the Zürich and Arizona ${ }^{14} \mathrm{C}$ series could not have removed all oil, whether fossil or modern, possibly introduced into the DSS fragments.

Lest the implications for Scroll studies be overlooked, this conclusion implies that the two series of ${ }^{14} \mathrm{C}$ datings of the DSS that have been conducted up to the present (Bonani et al. 1992 and Jull et al. 1995) cannot be guaranteed to have removed all of the modern carbon present in any samples if they had been contaminated with castor oil and hence could have produced some ${ }^{14} \mathrm{C}$ dates that were younger than the texts' true ages.

It is therefore necessary to devise a revised cleaning procedure capable of removing all castor oil in order to enable individual Qumran text ${ }^{14} \mathrm{C}$ datings to be relied upon with confidence. It remains to be seen whether a similar conclusion applies to DSS samples that have been treated with British Museum Leather Dressing.

\section{REFERENCES}

Bonani G, Ivy S, Wölfli W, Broshi M, Carmi I, Strugnell J. 1992. Radiocarbon dating of fourteen Dead Sea Scrolls. Radiocarbon 34(3):843-49.

Boyd-Alkalay E, Libman E. 1998. Preserving the Dead Sea Scrolls and Qumran artifacts. In: Flint P, Vanderkam J, editors. The Dead Sea Scrolls after 50 years. Brill: Leiden et al.:p 535-44.

Caldarero N. 1995. Storage conditions and physical treatments relating to the dating of the Dead Sea Scrolls. Radiocarbon 37(1):21-32.

Doudna G. 1998. Dating the scrolls on the basis of radiocarbon analysis. In: Flint P, Vanderkam J, editors. The Dead Sea Scrolls after 50 years. Brill: Leiden et al. p
430-71.

Doudna G. 1999. Redating the Dead Sea Scrolls found at Qumran: the case for 63 BCE. The Qumran Chronicle: 8(4). Special issue.

Mook W, van der Plicht J. 1999. Reporting ${ }^{14} \mathrm{C}$ Activities and Concentrations. Radiocarbon 41(3):227-39.

Jull AJT, Donahue DJ, Broshi M, Tov E. 1995. Radiocarbon dating of scrolls and linen fragments from the Judean desert. Radiocarbon 37(1):11-19.

Stuiver M, Reimer PJ, Bard E, Beck JW, Burr GS, Hughen KA, Kromer B, McCormac G, van der Plicht J, Spurk M. 1998. Radiocarbon 40(3):1041-84. 